\title{
PENGARUH MODEL PEMBELAJARAN PROBING-PROMPTING TERHADAP SIKAP SOSIAL PADA MATA PELAJARAN SISWA KELAS VIII SMP NEGERI 2 TARAKAN
}

\section{The Effect of Probing-Prompting Learning Model on Students' Social Attitudes in Science Learning Grade VIII SMP Negeri 2 Tarakan}

\author{
Nurasiah $^{\mathrm{a}}$, Ibrahim $^{\mathrm{b} *}$, Ermawaty Maradhy $^{\mathrm{b}}$ \\ a Mahasiswa S1 Program Studi Pendidikan Biologi, Universitas Borneo Tarakan, Tarakan, Kalimantan Utara \\ b Program Studi Pendidikan Biologi, Universitas Borneo Tarakan, Tarakan, Kalimantan Utara \\ ${ }^{*}$ Corresponding author: Jl. Amal Lama, Tarakan Timur, Tarakan, Kalimantan Utara, 77123, Indonesia. E-mail: \\ ibrahim_top77@borneo.ac.id
}

\begin{abstract}
Abstrak
Tujuan penelitian ini adalah untuk mengetahui pengaruh model pembelajaran probingprompting terhadap sikap sosial. Penelitian ini dilakukan pada bulan SeptemberDesember 2015 di SMPN 2 Tarakan. Penelitian ini adalah eksperimen semu dengan populasi siswa kelas VIII dan sampel sebanyak 2 kelas. Pengambilan sampel menggunakan teknik Purposive sampling. Teknik pengumpulan data menggunakan lembar penilai diri. Data dianalisis menggunakan uji Independent Sample T-Test dan uji regresi linear sederhana dengan menggunakan sofiware SPSS 16 for Windows. Hasil uji$\mathrm{t}$ sikap sosial diperoleh thitung 2,045 lebih besar dari $t_{\text {table }}(1,671)$. Hasil uji regresi linear sederhana menunjukan bahwa aktivitas probing-prompting berpengaruh positif terhadap sikap sosial siswa dengan kontribusi sebesar $12,0 \%$.
\end{abstract}

\section{Kata kunci}

Probing-Prompting, Sikap Sosial

\begin{abstract}
The aim of this study is to know the effect of probing-prompting learning model on social attitudes of students. This study was implemented on September-December 2015 in SMPN 2 Tarakan. This study was quasi experiment, and the population of this study was Grade VIII students. In addition, the sample that was used in this study was 2 classes (control \& experiment group). Data were analyzed using independent sample t-test, and regression test through SPSS 16 for Windows. The result of $t$-test showed $t_{\text {count }} 2,045$ is more higher than $t_{\text {table }} 1,617$. Additionally, regression test showed that the probing-prompting model have positive effect on social attitudes of students with a contribution of $12,0 \%$.
\end{abstract}

Keywords

Probing-Prompting, Social Attitudes 


\section{Pendahuluan}

Kurikulum 2013 merupakan serentetan rangkaian penyempurnaan terhadap kurikulum yang telah dirintis tahun 2004 yang berbasis kompetensi lalu diteruskan dengan kurikulum 2006 (KTSP). Orientasi pengembangan kurikulum 2013 adalah tercapainya kompetensi yang berimbang antara sikap, keterampilan, dan pengetahuan akan berbasis pendekatan saintifik. Untuk mendukung pendekatan ini, maka diperlukan model pembelajaran yang sesuai.

Salah satu model pembelajaran yang dapat digunakan adalah model ProbingPrompting. Menurut arti katanya, probing adalah penyelidikan, pemeriksaan. Penyelidikan atau pemeriksaan disini bertujuan untuk memperoleh sejumlah informasi yang telah ada pada diri siswa agar dapat digunakan untuk memahami pengetahuan atau konsep baru (Suhendra, 2012). Sementara itu, Prompting menurut arti kata berarti mendorong atau menuntun. Dengan kata lain prompting adalah cara lain dalam merespon jawaban siswa apabila siswa gagal menjawab pertanyaan, atau jawaban kurang sempurna. Dengan demikian salah satu bentuk prompting adalah menanyakan pertanyaan lain yang lebih sederhana yang jawabannya dapat dipakai menuntun siswa untuk menemukan jawaban yang tepat (Tjetjep dalam Nurjannah, 2013). Probing-prompting adalah suatu model pembelajaran yang berpusat pada pebelajar (student centered). Model pembelajaran ini sesuai dengan paham konstruktivis yang memberikan keleluasaan pada peserta didik untuk aktif mengkonstruksi pengetahuan sendiri. Guru hanya menjadi fasilitator dan mediator dalam setiap pembelajaran (Swarjawa, 2012).

Hasil observasi di SMP Negeri 2 Tarakan diketahui bahwa implementasi kurikulum 2013 dilakukan secara bertahap. Dibutuhkan model pembelajaran yang dapat meningkatkan hasil belajar siswa dan mengaktifkan siswa, sekaligus untuk membantu penerapan kurikulum 2013. Salah satu model pembelajaran yang cocok dan belum pernah diterapkan di SMP Negeri 2 Tarakan adalah model pembelajaran Probing-Prompting.

Beberapa hasil penelitian menunjukan bahwa model pembelajaran probingprompting dapat melatih siswa mengemukakan pendapat, mengkonstruksikan pengetahuan, serta dapat menemukan dan memecahkan permasalahan yang dihadapinya (Swarjawa, 2013). Penggunanan model pembelajaran probing-prompting secara efektif dapat memabantu penerapan kurikulum 2013 (Utami, 2016; Lutfiana, 2018). Pada penelitian ini, pembelajaran di fokuskan pada aktivitas probing-prompting terhadap hasil belajar sikap sosial siswa. Untuk itu, perlu dilakukan penelitian mengenai pengaruh model pembelajaran probing-prompting terhadap hasil belajar siswa, sehingga penelitian ini bertujuan untuk mengetahui apakah model pembelajaran probing-prompting berpengaruh terhadap hasil belajar siswa. 


\section{Material dan metode}

Jenis penelitian yang di gunakan oleh peneliti adalah kuasi eksperimen (quasi experimental), dan rancangan penelitian yang digunakan Posttest Only Non Equivalent Control Group. Penelitian ini dilaksanakan di SMP Negeri 2 Tarakan pada semester ganjil tahun ajaran 2014/2015 (10 September- 10 Desember 2014). Populasi pada penelitian ini adalah seluruh siswa kelas VIII SMP Negeri 2 Tarakan yang berjumlah 9 kelas. Sampel dalam penelitian ini berjumlah 2 kelas yaitu kelas kontrol (VIII-H) berjumlah 36 siswa dan kelas eksperimen (VIII-J) berjumlah 34 siswa. Teknik pengambilan sampel dalam penelitian ini adalah purposive sampling, yaitu penentuan sampel berdasarkan tujuan dan pertimbangan tertentu. Variabel bebas $(\mathrm{X})$ dalam penelitian ini adalah model pembelajaran Probing-Prompting, sedangkan variabel terikat (Y) adalah hasil belajar sikap sosial siswa. teknik pengumpulan data berupa dokumentasi, aktivitas probing-prompting dan penilaian diri sikap sosial siswa. Data tersebut dianalisis menggunakan uji independent sample T-test dan regresi linear sederhana.

\section{Hasil dan Diskusi}

Pengambilan data sikap sosial menggunakan lembar penilaian diri dengan penilaian skala Likert. Kelas kontrol dan kelas eksperimen diberikan posstest. Masing-masing siswa mengisi lembar penilaian diri. sikap sosial setelah proses pembelajaran berlangsung. Hasil penelitian hasil belajar sikap sosial dapat dilihat pada tabel 1.

Tabel 1. Nilai Rata-Rata hasil belajar sikap sosial

\begin{tabular}{ccc}
\hline \multirow{2}{*}{ Hasil Belajar } & \multicolumn{2}{c}{ MEAN (RATA-RATA) Postest } \\
\cline { 2 - 3 } & Kelas Eksperimen & Kelas Kontrol \\
\hline Sikap Sosial & 3.100 & 3.077 \\
\hline
\end{tabular}

Berdasarkan tabel 1 dapat diketahui bahwa nilai rata-rata sikap sosial kelas eksperimen lebih tinggi daripada kelas kontrol.

Untuk mengetahui apakah rata-rata hasil belajar siswa di kelas eksperimen dan kelas kontrol menunjukkan adanya perbedaan yang signifikan menggunakan uji t. Hasil output SPSS versi 16 untuk uji perbedaan rata-rata hasil belajar di kelas eksperimen dan kelas kontrol menggunakan uji t digambarkan pada Tabel 2.

Tabel 2. Uji Independent Sample T-Test Sikap Sosial

\begin{tabular}{|c|c|c|c|c|c|c|c|c|c|c|}
\hline & & \multicolumn{4}{|c|}{$\begin{array}{l}\text { Levene's Test } \\
\text { for Equality } \\
\text { of Variances }\end{array}$} & \multicolumn{3}{|c|}{ t-test for Equality of Means } & \multirow{2}{*}{\multicolumn{2}{|c|}{$\begin{array}{c}95 \% \text { Confidence } \\
\text { Interval of the } \\
\text { Difference }\end{array}$}} \\
\hline & & \multirow[t]{2}{*}{$\mathrm{F}$} & \multirow[t]{2}{*}{ Sig. } & \multirow[t]{2}{*}{$\mathrm{T}$} & \multirow[t]{2}{*}{ Df } & \multirow[t]{2}{*}{$\begin{array}{l}\text { Sig. (2- } \\
\text { tailed) }\end{array}$} & \multirow[t]{2}{*}{$\begin{array}{c}\text { Mean } \\
\text { Difference }\end{array}$} & \multirow[t]{2}{*}{$\begin{array}{l}\text { Std. Error } \\
\text { Difference }\end{array}$} & & \\
\hline & & & & & & & & & Lower & Upper \\
\hline \multirow[t]{2}{*}{$\mathrm{Y} 2$} & $\begin{array}{l}\text { Equal variances } \\
\text { assumed }\end{array}$ & .014 & .907 & 2.045 & 68 & .045 & .15180 & .07423 & .00368 & .29991 \\
\hline & $\begin{array}{l}\text { Equal variances } \\
\text { not assumed }\end{array}$ & & & 2.046 & 67.866 & .045 & .15180 & .07420 & .00374 & .29986 \\
\hline
\end{tabular}


Vol. 1 No. 2, 2019; pp. 117-123

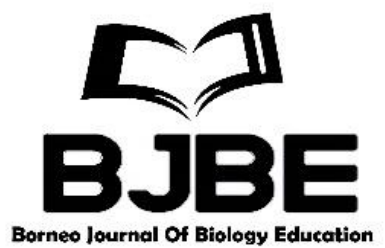

P-ISSN: 2715-6826 (print); E-ISSN: 2714-6073 (online)

Received: $12 / 07 / 2020$

Revised: 09/08/2020

Accepted: 15/10/2020

Dari tabel 2 pada baris equal variances assumed diperoleh thitung 2,045 pada taraf signifikansi $\alpha=0,05$ dan $\mathrm{dk}=68$ diperoleh nilai $\mathrm{t}_{\text {table }} 1,671$ berarti $\mathrm{t}_{\text {hitung }}>\mathrm{t}_{\mathrm{tabel}}$, artinya terdapat perbedaan hasil belajar sikap sosial siswa kelas eksperimen yang belajar dengan model pembelajaran probing-prompting dan siswa kelas kontrol yang hanya belajar dengan pembelajaran kurikulum 2013. Melalui pembelajaran probing-prompting, siswa berfikir aktif, melakukan diskusi untuk merumuskan jawaban atau memecahkan permasalahan yang dihadapi, mengembangkan keterampilan, dan dapat mengkonstruksikan pengetahuan yang telah ada pada diri siswa dan konsep baru yang sedang dipelajari, hal ini sesuai dengan pendapat Suhendra (2012) yang menyatakan bahwa probing adalah penyelidikan, pemeriksaan, sedangkan prompting adalah mendorong atau menuntun. Penyelidikan atau pemeriksaan disini bertujuan untuk memperoleh sejumlah informasi yang telah ada pada diri siswa agar dapat digunakan untuk memahami pengetahuan atau konsep baru.

Untuk mengetahui sebesarapa besar pengaruh model pembelajaran probingprompting terhadap hasil belajar sikap sosial siswa. Data dianalisis menggunakan regresi linear sederhana. Hasil regresi linear sederhana dengan menggunakan SPSS 16 disajikan dalam Tabel 3.

Tabel 3. Perhitungan regresi linear sederhana.

\begin{tabular}{llrrrrr}
\hline \multicolumn{1}{c}{ Model } & $\begin{array}{c}\text { Sum of } \\
\text { Squares }\end{array}$ & Df & Mean Square & F & Sig. \\
\hline 1 & Regression & .192 & 1 & .192 & 4.380 & $.044^{\mathrm{a}}$ \\
& Residual & 1.403 & 32 & .044 & & \\
& Total & 1.594 & 33 & & & \\
\hline
\end{tabular}

Dari data pada tabel 3 diperoleh nilai signifikan $0.044<0.05$ yang berarti $\mathrm{H}_{0}$ di tolak. Hal ini dapat membuktikan hipotesis tersebut yakni ada pengaruh model pembelajaran probingprompting terhadap hasil belajar sikap sosial siswa.

Hasil output koefisien persamaan regresi dapat dilihat pada Tabel 4. Dari data pada Tabel 4 dapat dirumuskan persamaan regresi data tersebut adalah $\hat{Y}=1,813+0,335 X$. Dengan $\hat{Y}$ merupakan hasil sikap sosial dan $\mathrm{X}$ adalah skor aktivitas probing-prompting siswa. Hal tersebut berarti apabila tidak ada aktivitas probing-prompting siswa terhadap sikap sosial siswa maka nilai sebesar 1,813, dan apabila skor aktivitas probing-prompting siswa terhadap sikap sosial siswa bertambah satu angka, maka nilai $\hat{Y}$ bertambah sebesar 0,335 .

Tabel 4. Koefesien persamaan regresi

\begin{tabular}{|c|c|c|c|c|c|c|}
\hline & \multirow[t]{2}{*}{ Model } & \multicolumn{2}{|c|}{$\begin{array}{l}\text { Unstandardized } \\
\text { Coefficients }\end{array}$} & \multirow{2}{*}{$\begin{array}{c}\text { Standardized } \\
\text { Coefficients } \\
\text { Beta }\end{array}$} & \multirow[t]{2}{*}{$\mathrm{t}$} & \multirow[t]{2}{*}{ Sig. } \\
\hline & & $\mathrm{B}$ & Std. Error & & & \\
\hline \multirow[t]{2}{*}{1} & (Constant) & 1.813 & .448 & & 4.043 & .000 \\
\hline & X.Aktivitas & .335 & .160 & .347 & 2.093 & .044 \\
\hline
\end{tabular}


Vol. 1 No. 2, 2019; pp. 117-123

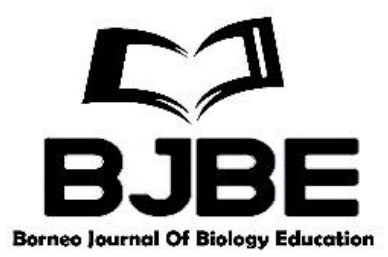

P-ISSN: 2715-6826 (print); E-ISSN: 2714-6073 (online)

Received: $12 / 07 / 2020$

Revised: 09/08/2020

Accepted: 15/10/2020

Berdasarkan Gambar 1 dapat diketahui bahwa arah korelasi antara variabel X dengan variabel $\mathrm{Y}_{2}$ adalah korelasi yang positif. Korelasi positif menyatakan bahwa semakin besar nilai pada variabel $\mathrm{X}$, diikuti pula perubahan dengan semakin besar nilai pada variabel $\mathrm{Y}$.

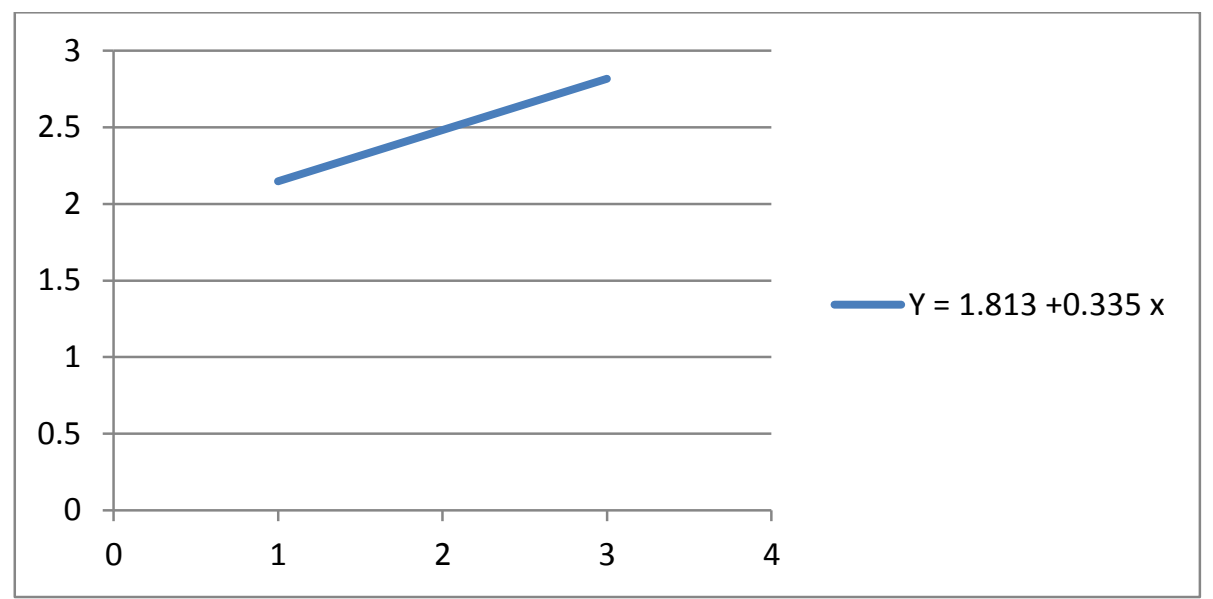

Gambar 1. Garis linear antara variabel y dan x

Berdasarkan grafik 4.2 dapat diketahui bahwa arah korelasi antara variabel $\mathrm{X}$ dengan variabel $\mathrm{Y}_{2}$ adalah korelasi yang positif. Korelasi positif menyatakan bahwa semakin besar nilai pada variabel $\mathrm{X}$, diikuti pula perubahan dengan semakin besar nilai pada variabel $\mathrm{Y}$.

Untuk melihat seberapa kuat hubungan antara kedua variable dan untuk melihat seberapa besar variabel hasil belajar sikap sosial $\left(\mathrm{Y}_{2}\right)$ dipengaruhi oleh variabel aktivitas probing-prompting $(\mathrm{X})$ dapat dilihat pada Tabel 5.

Tabel 5. Output Model Summary

\begin{tabular}{|c|c|c|c|c|c|}
\hline Model & $\mathrm{R}$ & $\begin{array}{c}\mathrm{R} \\
\text { Square }\end{array}$ & $\begin{array}{l}\text { Adjusted } \\
\text { R Square }\end{array}$ & $\begin{array}{l}\text { Std. Error } \\
\text { of the } \\
\text { Estimate }\end{array}$ & $\begin{array}{l}\text { Durbin- } \\
\text { Watson }\end{array}$ \\
\hline 1 & $.347^{\mathrm{a}}$ & .120 & .093 & .20935 & 1.269 \\
\hline
\end{tabular}

Dari data tabel 5. Besarnya nilai $R$ yaitu 0,347 berada diantara $0,20-0,39$ maka dapat disimpulkan bahwa korelasi antara hasil belajar sikap sosial (Y) dengan aktivitas probingprompting $(\mathrm{X})$ tergolong rendah. Nilai koefesien determinasi dapat dibaca pada nilai $\mathrm{R}$ square. Besarnya nilai R Square atau $\mathrm{r} 2=0,120=12,0 \%$ menunjukkan bahwa skor aktivitas probing-prompting siswa mempengaruhi sikap sosial siswa sebesar $12,0 \%$. 


\section{Kesimpulan}

Berdasarkan hasil dan pembahasan dapat disimpulkan bahwa model pembelajaran Probing-Prompting berpengaruh positif terhadap hasil belajar sikap sosial kelas VIII SMP Negeri 2 Tarakan. Berdasarkan perhitungan dengan uji t untuk mengetahui adanya perbedaan kompetensi pedagogik dan sikap sosial siswa, didapatkan hasil bahwa kelas ekseprimen dan kontrol berbeda berdasarkan rata-rata. Hasil output koefisien persamaan regresi didapatkan nilai $\hat{Y}=1,813+0,335 \mathrm{X}$. Hal tersebut berarti apabila tidak ada aktivitas probing-prompting siswa terhadap sikap sosial siswa maka nilai sebesar 1,813, dan apabila skor aktivitas probing-prompting siswa terhadap sikap sosial siswa bertambah satu angka, maka nilai $\hat{Y}$ bertambah sebesar 0,335 . Besarnya nilai $R$ yaitu 0,347 berada diantara 0,20 0,39 maka dapat disimpulkan bahwa korelasi antara hasil belajar sikap sosial (Y) dengan aktivitas probing-prompting $(\mathrm{X})$ tergolong rendah.

\section{Daftar Pustaka}

Arikunto, Suharsimi. (2012). Dasar-Dasar Evaluasi Pendidikan Edisi 2. Jakarta. Bumi Aksara,

Hamalik, O. (2012). Psikologi Belajar dan Mengajar. Sinar Baru Algensindo, Bandung.

Hartono. (2012). Statistik untuk Penelitian. Pustaka Pelajar, Yogyakarta.

Hartono, R. (2013). Ragam Model Mengajar yang Mudah diterima Murid. DIVA Press, Jogjakarta.

Haryati, M. (2013). Model Dan Teknik Penilaian Pada Tingkat Satuan Pendidikan. Penerbit Referensi, Jakarta.

Hasan, I. (2009). Analisis Data Penelitian dengan Statistik. PT. Bumi Aksara, Jakarta.

Kurinasih, I. \& Sani, B. (2014). Implementasi Kurikulum 2013 Konsep dan Penerapan. Kata Pena, Surabaya.

Lutfiana, N. (2019). Efektivitas model pembelajaran probing prompting terhadap penguasaan konsep ditinjau dari perbedaan gender pada mata pelajaran IPA (Doctoral dissertation, UIN Raden Intan Lampung).

Nurjannah, S. 2013. Efektivitas Model Pembelajran Course Review Horay dan ProbingPrompting Berbasis The Power Two Berbantu CD Interaktif Di Tinjau Dari Hasil Belajar Dan Jenis Kelamin. Skripsi. Fakultas Pendidikan Matematika Dan Ilmu Pengetahuan Alam IKIP PGRI Semarang.

Nasution. (2003). Metode Penelitian Naturalistik Kualitatif. TARSITO, Bandung. 
Vol. 1 No. 2, 2019; pp. 117-123

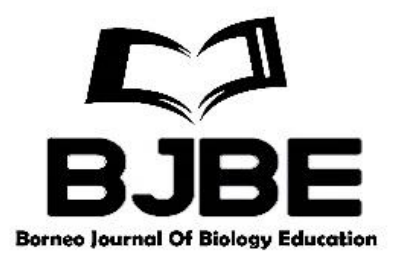

P-ISSN: 2715-6826 (print); E-ISSN: 2714-6073 (online)

Received: $12 / 07 / 2020$

Revised: 09/08/2020

Accepted: 15/10/2020

Permendikbud No. 54 Tahun 2013 tentang Standar Kompetensi Lulusan.

Permendikbud No. 66 Tahun 2013 tentang Standar Penilaian.

Permendikbud RI No. 81A Tahun 2013 tentang Pedoman Implementasi Kurikulum.

Santiningtyas, K., Prasetyo, A. P. B., \& Priyono, B. (2012). Pengaruh Outdoor Learning Berbasis Inkuiri terhadap Hasil belajar Materi Ekosistem. Unnes Journal of Biology Education, 1(2), 91-98.

Sudjana, Nana. (2011). Penilaian Hasil Belajar Mengajar. Remaja Rosdakarya, Bandung. Sugiyono. (2011). Statistika untuk Penelitian. Alfabeta, Bandung.

Sugiyono. (2013). Metode Penelitian Kombinasi (Mixed Methods). Alfabeta, Bandung.

Suhendra, A. (2012). Penerapan Model Pembelajaran Probing-Prompting Menggunakan Media Peta Konsep untuk Meningkatkan Hasil Belajar Siswa Pada Pokok Bahasan Hidrokarbon. Skripsi.Universitas Negeri Medan.

Sulistyo, J. (2011). Enam Hari Jago Spss 17. Cakrawala, Jogjakarta.

Swarjawa, I. W. E., Suarjana, M., \& Garminah, N. N. (2013). Pengaruh Model Pembelajaran Probing-Prompting Terhadap Hasil Belajar IPA Siswa Kelas V di SD Negeri 1 Sebatu. MIMBAR PGSD Undiksha, 1(1).

Utami, D. (2016). Penerapan Model Pembelajaran Probing Prompting dalam Pembelajaran Mengabstraksi Teks Negosiasi pada Siswa Kelas X SMA/MA. Riksa Bahasa: Jurnal Bahasa, Sastra, dan Pembelajarannya, 2(2).

Zubaidah, S., Mahanal, S., Yuliati, L., \& Sigit, D. (2014). Buku Guru Ilmu Pengetahuan Alam SMP/MTs Kelas VIII. Jakarta: Kemendikbud. 
